\title{
Intrathecal Analgesia Via a Percutaneous Port For the Management of Movement-Evoked Breakthrough Cancer Pain of Refractory Lower Extremity Cancer Pain: A Retrospective Review and Commentary
}

\section{Liang Zhou}

Peking University Shougang Hospital

Zhenggang Guo ( $\nabla$ shouganggzg@163.com )

Peking University Shougang Hospital

\section{Research Article}

Keywords: movement-evoked breakthrough pain, patient-controlled intrathecal analgesia, lower extremity Cancer Pain, Intrathecal morphine infusion therapy via percutaneous port

Posted Date: November 15th, 2021

DOI: https://doi.org/10.21203/rs.3.rs-885466/v1

License: (c) (1) This work is licensed under a Creative Commons Attribution 4.0 International License. Read Full License 


\section{Abstract}

Background and Objectives: Intrathecal analgesia (ITA) is a trusty treatment option for refractory and intractable cancer pain. However, there is still no general consensus on the analgesic effect of movementevoked breakthrough pain (MEBTP) in the ITA setting. This study examined the effect of patientcontrolled intrathecal analgesia (PCIA) on analgesic efficacy, emphasizing movement evoked breakthrough pain (MEBTP) in patients with refractory lower extremity cancer pain.

Methods: A retrospective chart review included all patients with refractory lower extremity cancer pain who received Intrathecal morphine infusion therapy via percutaneous port (IMITPP) at our hospital between January 2017 and December 2020. Data on the numerical pain rating scales (NRS) scores, opioid doses, and complications were collected from medical records prior to IMITPP and at a one-month postimplant visit.

Results: A total of 16 patients were included in the study group. Mean SRPI (spontaneous resting pain intensity) decreased from 8.75 pre- IMITPP to 3.75 post- IMITPP, $(\mathrm{P}<0.001)$; mean MEPI (movementevoked breakthrough pain intensity) fell from 8.83 pre- IMITPP to 4.25 post- IMITPP $(P<0.001)$; mean daily morphine equivalent dosing decreased from $360 \mathrm{mg} / \mathrm{d}$ to $48 \mathrm{mg} / \mathrm{d}(P<0.001)$; mean daily morphine equivalent dosing for MEBTP decreased from $87 \mathrm{mg} / \mathrm{d}$ to $6 \mathrm{mg} / \mathrm{d}(P<0.001)$. Both total and breakthrough dosing of conventional opioid medications significantly decreased following the initiation of ITT with $\mathrm{PCIA}$. The mean perceived time to onset with conventional movement evoked breakthrough medications was 38 minutes, and the mean perceived time to onset with PCIA was 8 minutes $(P<0.001)$.

Conclusions: IMITPP was associated with improved pain control in patients with refractory lower extremity cancer pain. Compared with conventional MEBTP medication, appropriate PCIA provided superior analgesia and a much faster onset of action.

\section{Introduction}

Cancer-associated pain continues to present a significant problem, with a prevalence of up to $67 \%$ [1]. With the popularization and application of World Health Organization (WHO) "ladder" of pain management, the treatment of cancer pain has made great progress $[2,3]$. However, about $20 \%$ of patients are still not satisfied with their pain control, even when treatment is standardized according to WHO analgesic ladder [4]. In a prospective study that included 2118 patients with cancer-related pain managed by the $\mathrm{WHO}$ analgesic ladder, $3 \%$ required intrathecal or epidural analgesia [5]. It is generally accepted that IT therapy provides a safe and efficacious treatment for cancer pain and end -of-life pain care [6-8].

Severe lower extremity pain is the main symptom of bone and soft tissue malignancies and bone metastatic tumors [9-11], while movement evoked breakthrough pain (MEBTP) is widely recognized as the most difficult-to-treat clinical problem in these patients [12]. BTP can be categorized into spontaneous BTP, end-of-dose failure, and incident pain, with movement evoked breakthrough pain (MEBTP) being a 
subtype $[13,14]$. Due to fear of MEBTP, patients are afraid or unwilling to change body position, as this may bring a series of problems, including incision non-healing, pressure sores, lung infection, urinary retention, and similar. More importantly, this may hinder patients' cooperation with routine examinations, as well as affect tumor evaluation and follow-up treatment. Although there have been some studies on ITA treatment of MEBTP, the reported conclusions are not consistent. Also, the issue of movement evoked BTP on lower limb has been poorly investigated in the ITA setting [15-17].

Due to its relatively lower cost, Intrathecal morphine infusion therapy via percutaneous port (IMITPP) may be a better option for cancer patients with a shorter predicted survival than via an implantable morphine pump $[18,19]$. IMITPP is a percutaneous port attached to an external drug infusion pump that allows for continuous intrathecal analgesia for the management of spontaneous resting pain (SRP), patientcontrolled intrathecal analgesia (PCIA) for the management of movement evoked breakthrough pain (MEBTP) and/or self-titrate to analgesic effect $[16,20]$. In this study, we analyzed the medical records of patients with lower limb cancer pain recently admitted to our hospital, all of whom used IMITPP. We hypothesized that PCIA could not only increase the number of activities in patients and shorten the response time to deal with MEBTP, but it also improves overall pain relief and opioid-related adverse effects. In our study, we performed a retrospective review of patients who received IMITPP to refractory lower extremity cancer pain in China to verify our hypothesis and provide a useful reference for diagnosis and treatment of refractory lower extremity pain caused by a malignant bone tumor.

\section{Materials And Methods Patient Population}

Between January 2017 and December 2020, IMIPTT was performed for 70 patients with advanced cancer pain, 16 of whom were refractory lower extremity cancer pain patients implanted with an intrathecal catheter connected to a percutaneous port (Beijing Yuetong medical apparatus and instruments, Inc, Beijing, China) for IMITPP. Four patients were excluded from the study for the following reasons: 2 patients died within 1 month of catheter implantation; 1 patient who suffered from mania could not use PCIA and follow the requirements; 1 patient underwent notch split because of targeted therapy. Finally, 12 patients were included in the analyses. All procedures were performed by the same physician at the Shougang hospital, Peking University, and under strict sterile operating room conditions with the patient under local anesthesia.

Lumbar subarachnoid puncture and catheterization were performed under X-ray guidance. The soft catheter with metal guide wire was implanted into the subarachnoid space, and the tip of the catheter was placed at T12(The 12th thoracic vertebra) level that was considered to best subserve the dermatomal distribution of the patient's lower extremity pain (data on pain location and catheter tip location are shown in Table 2). Then, the subcutaneous port was usually placed on the costal margin of the midline of the clavicle on one side, and the catheter was connected to a subcutaneous port via the subcutaneous tunnel. Morphine and bupivacaine diluted with $0.9 \%$ sodium chloride solution to $250 \mathrm{~mL}$ 
(Qinghai Pharmaceuticals, Xining, China) were infused into intrathecal space through the subcutaneous port by an external drug infusion pump (ACEMEDICAL Co., Inc., Gyeoggi-Do, Korea)[21, 22]. The dosing of intrathecal morphine was based on guidelines and clinical experience. Opioids given by traditional routes were then gradually reduced or quickly weaned off before the patients were discharged from the hospital.

\section{Data Collection}

All data of this retrospective review were obtained from electronic medical records including patients' demographic data, types of cancer, technical data (such as insertion interspace, catheter tip location), and complications related to IMITPP. Numerical pain rating scales (NRS) scores and doses of opioids before and after IMITPP were also determined. To attempt to evaluate the treatment effect of MEBTP, the use of immediate-release as-needed opioid medications was also listed and compared.

Outcome data were also obtained from follow-up appointments. A follow-up visit at 4 weeks after port implantation was selected as the best appropriate time for postimplant data collection. This time period was selected to ensure that postoperative incisional pain did not impact pain assessment and that adequate dose titration of the intrathecal medications was obtained. Medication data before and after port implantation were recorded in medical files of our institution such as the initial evaluation documentation and pharmacy drug reconciliation data for all patients. Following port implantation, the pump was interrogated at each follow-up, and all pump data were recorded in the patient chart.

\section{Statistical Methods}

Summary statistics (number, mean, standard deviation/error) were provided for age, gender, type of cancer, months since diagnosis, the reason for ITA, morphine oral equivalent dosing, patients using MEBTP medications, baseline NRS score, months since diagnosis, and period of IMITPP. Frequency tables are provided for each categorical variable (oral morphine equivalent opioid dosing, intrathecal morphine, and bupivacaine dosing (including PCIA), NRS scores, onset time for MEBTP, and pump data). The primary outcome variable was the change in NRS pain scores, including SRPI (spontaneous resting pain intensity) and MEPI (movement-evoked breakthrough pain intensity) before and after the ITT was commenced. The second outcome variable was the change in onset time for MEBTP. The third outcome variable was the increase of intrathecal medication, including PCIA in MEBTP medication use. In addition, a comparison of morphine equivalent opioid dosing before and after ITT was performed. Changes in the use of oral analgesics were compared using the Wilcoxon signed-ranks test to evaluate the paired nonnormally distributed data, and Paired Sample t-test was used to evaluate data with normal distribution, including NRS scores, onset time for MEBTP and intrathecal data. $\mathrm{P}<0.05$ was considered to be statistically significant.

\section{Results}

\section{Study Population}


The final study population included 12 patients who received placement of an intrathecal catheter for cancer pain. All patients could control breakthrough pain by using their external pump system. The follow-ups occurred from January 2017 to December 2020. The average follow-up period for data collection was 6 weeks. All demographic data are listed in Table 1. Osteosarcoma and fibrosarcoma were the most common types of cancer. Unsatisfied pain control was the most common reason for ITT. Other indications included intolerance of oral or transdermal opioids due to nausea, sedation, or refractory constipation.

All patients were using opioids for control of MEBTP. Mean NRS pain scores were $8 \pm 0.3$ at the initial evaluation. The mean time for all patients until death was $3.5 \pm 1.9$ months. The data on patients' treatment, including age, diagnosis, pain site, catheter tip location, and their intrathecal regimen at followup, are summarized and shown in Table 1.

\section{Patient-Reported Pain Scores and perceived time to onset}

Between T0 and T1m, the distributions of the worst pain and the perceived time of onset are shown in Figure 1 and Figure 2. Mean SRPI decreased from 8.75 to 3.75; mean MEPI dropped from 8.83 to 4.25; the observed difference was statistically significant $(P<0.001)$. The mean perceived time to onset with conventional MEBTP medications was $38.75 \pm 14.63$ minutes (range, 20-60 minutes), and the mean perceived time to onset with PCIA was $8 \pm 2.21$ minutes (range, 5-12 minutes). The t-test PAIRS revealed a significantly faster onset of analgesia with PCIA $(P<0.001)$. Further details are shown in Table 2.

\section{Nonintrathecal Opioid Medication Use}

All except 1 patient who could not tolerate any oral pain medications were on three- step opioid therapy before ITT performance. Before ITT, patients were taking a mean oral morphine equivalent to $360 \mathrm{mg} / \mathrm{day}$ (range: $90-800 \mathrm{mg} /$ day). Following the catheter placement, the dose was lowered to $48 \mathrm{mg} /$ day (range: $0-120 \mathrm{mg} /$ day; $P<0.001$ ). Before ITT, the patients were taking an average of $87 \mathrm{mg} /$ day (range: $20-200$ $\mathrm{mg} /$ day) of oral morphine equivalent short-acting (parenteral, immediate oral release, or oral transmucosal) MEBTP medications for (MEBTP) movement-evoked breakthrough pain (including oxycodone, hydrocodone, morphine, fentanyl, hydromorphone). The dose for MBTP medication decreased to an average of $6 \mathrm{mg} /$ day (range: $0-20 \mathrm{mg}$ ) following the use of ITT $(P<0.001)$. After the initiation of ITT with PCIA, both total and breakthrough dose for conventional opioid medications significantly decreased. The specific data are summarized in Table 3.

\section{Intrathecal Pump Medications}

All 12 patients included in our study got a mixture of morphine and local anesthetic (bupivacaine) as an effective part of their intrathecal regimen. Intrathecal drug regimens are summarized in Table 4. All patients had the option of using PCIA to treat their breakthrough pain. Patients had a significant increase in intrathecal medication, including morphine and bupivacaine, on postoperative 30 days compared to baseline. The patients were taking an average of Intrathecal opioids from $1.85 \mathrm{mg}$ to $27.87 \mathrm{mg}$, including PCIA morphine from $0.65 \mathrm{mg}$ to $12.73 \mathrm{mg}$. The patients were taking an average of intrathecal bupivacaine 
ranging from $0.94 \mathrm{mg}$ to $14.54 \mathrm{mg}$, including PCIA bupivacaine from $0.33 \mathrm{mg}$ to $6.48 \mathrm{mg}$. Patients used their PCIA device on average from 13.08 to 20.25 times a day. The average infusion speed of the pump increased from 0.11 to $0.99 \mathrm{ml} /$ hour. These data are summarized in Table 4.

\section{Opioid-related Side Effects and Technical Complications}

Table 5 presents the opioid-related side effects and technical complications before and after intrathecal treatment. Nausea and vomiting, constipation, and respiratory depression were the most frequently reported side effects of opioid administration. There were no significant changes in these effects compared to preoperative conditions. Two more patients had urinary retention compared to the preoperative state and were managed by temporary urinary catheterization. Two patients experienced a headache from a cerebrospinal fluid leak after a post-arachnoid puncture, which was successfully relieved in both patients after conservative treatments. No other complications of intrathecal drug delivery, including catheter kinking, catheter fracture/leakage, catheter migration, paresthesia on catheter threading, were observed.

\section{Discussion}

In some patients with extremity osteosarcoma and bone metastases, MEBTP has been widely recognized as the most difficult to treat by conventional medical management, including oral or transmucosal opioids [23, 24]. Intrathecal drug infusion therapy is an effective treatment selection for refractory cancer pain; however, the general consensus on its effectiveness for movement evoked BTP has not yet been reached $[16,25]$. The purpose of this study was to investigate the efficacy of ITA with PCIA in the treatment of MEBTP of lower extremity tumors.

High cost limited the use of the implanted intrathecal morphine pump despite it is more suitable for longterm use. Recently, intrathecal morphine infusion therapy via a percutaneous port (IMITPP) has become a popular option for refractory cancer pain in some countries for its relatively lower cost [19]. In the present study, we assessed the efficacy and safety of IMITPP.

Direct analgesic delivery to the neural axis offers immediate access to receptors, bypasses the bloodbrain barrier, and minimizes systemic drug interactions. A commonly used mixture for the treatment of intractable pain consists of morphine and bupivacaine. Nevertheless, IT bupivacaine also provides better analgesia in patients with neuropathic pain than in patients with nociceptive pain [22].

In their randomized controlled study, Bäckryd et al[25] evaluated an intrathecal drug delivery system versus comprehensive medical management to treat advanced cancer pain, reporting significant improvement in spontaneous resting pain intensity (SRPI). Nonetheless, MEBTP was not adequately controlled despite ITA. However, besides providing support that ITA is a valuable analgesic technique in spontaneous resting pain intensity (SRPI), our results also revealed that movement-evoked BTP could be adequately controlled in patients with lower extremity osteosarcoma and bone metastases. Since the main purpose of this study was to explore movement-evoked BTP, we chose the lower extremity pain with 
the greatest impact of movement-evoked BTP. Our results revealed that movement-evoked pain intensity significantly decreased after one month of treatment. The proportions of the drugs in the study have been approved. Still, differences in concentration and dose and the rate of administration could be the most important reason for the diametrically different results of the two studies. In the Bäckryd study [25], their initial dose of intrathecal morphine was adjusted according to pre-ITA doses using an oral-to-intrathecal ratio of 200:1. In the present study, we used the 300:1 ratio, which is in line with the PACC clinical recommendation [26]. Our intrathecal basal starting dose was less than or equal to their study. However, as they used a fully implantable PUMP with just $40 \mathrm{~mL}$ in volume, this limited the concentration and volume variation. The maximum capacity of the external PUMP we used was $250 \mathrm{ml}$, allowing us to configure the drug concentration flexibly. In their study, by a combination of morphine $(0.2 \mathrm{mg} / \mathrm{mL})$, bupivacaine $(1 \mathrm{mg} / \mathrm{ml})$ was infused intrathecally. The usual starting rate was $0.5 \mathrm{ml} / \mathrm{h}$ with patientcontrolled boluses of $0.2 \mathrm{~mL}$ available up to twice per hour as needed. In our study, the concentration of morphine $(0.1-0.8 \mathrm{mg} / \mathrm{mL})$, bupivacaine $(1 \mathrm{mg} / \mathrm{mL})$, and the dose of bolus were usually set to be consistent with the continuous infusion dose for one hour. The maximum speed was given to $2 \mathrm{ml} / \mathrm{h}$, which means that the maximum single bolus dose was $2 \mathrm{ml}$. The lockout period was $10-15$ minutes, so our single dose of bolus and the number of bolus were much higher than theirs, but the total dose we used was still within the safe range. At the same time, we customized the treatment for every patient and we always advised them to press the bolus button usually 5-10 minutes before their movement according to their pain intensity. Patient-controlled intrathecal analgesia offered the patient the ability to deliver a bolus of an opioid and local anesthetic to the neuraxis and produce rapid-onset analgesia.

Bäckryd et al. [25] suggested that metastatic bone pain was precisely movement that evoked BTP. The pathophysiology of metastatic bone pain was a complicated matter, but on a basic level, it was reasonable to assume that weight-bearing and movement increase the nociceptive input into the spinal cord. Furthermore, this increase in nociceptive input could occur, especially if there were incipient or actual pathologic fractures or substantial cancer growth into adjacent neural structures. Thus, it seemed that advanced breast or lung cancer with concomitant neuropathic pain was a risk factor for intractable MEBTP despite otherwise successful ITA.

All patients enrolled in our study were patients with lower limb tumors. More interestingly, in all the cancer pain patients we treated with intrathecal analgesia, lower extremity pain was more significantly relieved compared to patients with visceral neuralgia. For these patients, we placed the catheter in T12 due to the fact that spinal neuralgia was involved in more patients with lower limb pain, and sympathetic nerves and splanchnic autonomic nerves were less likely to be involved, which needs to be addressed by future studies.

In addition to the dose, we noticed that another critical factor for the treatment of MEBTP was the time of onset. Patients involved in this study were patients with lower limb tumors, most of whom had poor healing or infection of incision as they mostly underwent surgery, radiation, and chemotherapy, and targeted therapy. Meanwhile, most of the primary tumors or operative incisions were located in the lumbosacral portion or lower extremities. It was very important for these patients to regularly change 
position to reduce the incision site pressure, pressure sores, and so on. However, the most contradictory thing was the fear of patients due to the active MEBTP, and such patients were unwilling to simply move and change the position, which eventually led to the occurrence of serious complications such as incision rupture and necrosis, pressure sores, lung infection and so on, and eventually aggravated the development of the disease.

In their randomized controlled study, Brogan et al evaluated an intrathecal drug delivery system versus comprehensive medical management in the treatment of advanced cancer pain and compared it with conventional BTP analgesics, revealing PCIA to be associated with a 3-fold faster onset of action, improved efficacy, and high patient satisfaction [16]. We support their findings. In our study, we found that the onset time of ITA-controlled MEBTP was significantly shorter (from 38min to about $8 \mathrm{~min}$; $p<0.05)$. ITA dosages were subsequently adjusted according to clinical response but were not prospectively registered. In our daily clinical procedure, patients were instructed to use the bolus function for predictable movement-evoked pain, and the MEBTP could be well controlled. After doing that, we encouraged patients to take the initiative to change their position, thus further reducing the incidence of pressure sores and other complications. Our study revealed encouraging results, considering the active position change was significantly more frequent than in the past. In addition, the use of non-ITA opioids significantly decreased, and the intrathecal use of opioids significantly increased over time. These conclusions were consistent with those of previous studies.

Several studies have shown that intrathecal morphine infusion therapy reduces the incidence of the adverse advents caused by systemic opioids due to high morphine concentrations at the site of action. Several operative and drug-related complications may arise after implantation [27, 28]. Nausea and vomiting, constipation, and respiratory depression were the most frequently reported side effects of opioid administration [28]. In our study, there were no significant changes in these effects compared to the preoperative state. As most patients received systemic opioids in this study, some patients suffered from these side effects of opioids, and the fact that we did not observe the relief of these effects after IMIPTT may be due to the shorter observation time. Adverse effects of intrathecal morphine therapy are common during the initial stage of the treatment; however, these effects usually disappear with standard medical management during the first three months. On the other hand, we could see that IMIPTT did not increase the occurrence of these side effects compared with the traditional treatment. The incidence of drug-related side effects with long-term intrathecal morphine therapy decreases with medical management and dose reduction as therapy continues. Urinary retention following intrathecal morphine administration has an estimated incidence between $42 \%$ and $80 \%$. Yet, the incidence of urinary retention with long-term intrathecal morphine therapy has been reported to be $3 \%$ [18]. In this study, two more patients had urinary retention compared to preoperative conditions and were managed by temporary urinary catheterization, which was in accordance with the studies above. Two patients experienced a headache from a cerebrospinal fluid leak after a post-arachnoid puncture, which was relieved by conservative treatments. These two patients were unable to remain in the supine position but in the semidecubitus position even after the operation, which may be the important cause of postoperative headache. These symptoms quickly disappeared with fluid rehydration [29]. 
Inevitably, there are still some limitations in our study. First, only 12 patients were retrospectively evaluated. An effective analysis of intrathecal opioid efficacy was not possible because the power of such a small sample size was low. Second, it is a retrospective study without long-term follow-ups, which makes it difficult to assess the long-term complications of IMITPP. Therefore, it was not clear whether opioid-induced side effects were reduced following intrathecal therapy. Third, we only could use the NRS scoring system to assess pain without including a scale questionnaire and satisfaction survey according to the medical records in a retrospective study, which prevented us from fully evaluating the comprehensive situation of pain improvement. Therefore, we are currently collecting data in a prospective manner, including various quality of life metrics and breakthrough pain measurements to further investigate whether IMITPP with PCIA is superior for the management of refractory cancer pain and MEBTP.

\section{Conclusion}

The higher PCIA doses and numbers and predictive administration might lead to overall better results, even for MEBTP in patients with refractory lower extremity cancer pain. IMITPP does not increase the incidence of some adverse advents caused by systemic opioids; however, several operative and drugrelated complications may arise in the short term after implantation. A prospective study is urgently needed for a more accurate assessment of the efficacy of IMITPP with PCIA against MEBTP.

\section{Abbreviations}

Intrathecal analgesia (ITA) Movement-evoked breakthrough pain (MEBTP) patient-controlled intrathecal analgesia (PCIA) Intrathecal morphine infusion therapy via percutaneous port (IMITPP) Numerical pain rating scales (NRS) Spontaneous resting pain intensity) (SRPI) Movement-evoked breakthrough pain intensity(MEPI)

\section{Declarations}

\section{Ethics approval and consent to participate}

This study was approved by the ethics committee of Peking university shougang hospital with approval number [IRBW-2021-011-01]. The patient provided written consent. All methods were carried out in accordance with Declaration of Helsinki.

\section{Consent for publication}

Not applicable

\section{Availability of data and material}


All data generated or analysed during this study are included in this published article and its supplementary information files

\section{Competing interests}

The authors declare that they have no competing interests

\section{Funding}

Not applicable

\section{Authors' contributions}

Liang Zhou edited the manuscript to its present state and formulated the initial draft of the article. Zhenggang Guo contributed toward conception and provided critical revision of the manuscript.

\section{Acknowledgements}

Not applicable

\section{References}

1. Marieke H.J, L.M.J., Vivianne C.G,Daisy J.A, Update on Prevalence of Pain in Patients With Cancer: Systematic Review and Meta-Analysis, in J Pain Symptom Manage. 2016. p. 1070-1090 e9.

2. Lundorff, L., Peuckmann, V,Sjogren, P., Pain management of opioid-treated cancer patients in hospital settings in Denmark. Acta Anaesthesiol Scand, 2008. 52(1): p. 137-42.

3. Schug S A, Z.D., etc., Cancer pain management according to WHO analgesic guidelines. Joumal of Pain and Symptom Management, 1990. 5(1): p. 27-32.

4. Gough, N., A.B. Miah, and M. Linch, Nonsurgical oncological management of cancer pain. Curr Opin Support Palliat Care, 2014. 8(2): p. 102-11.

5. Zech DF, G.S., Lynch J, Hertel D and Lehmann KA, Validation of World Health Organization Guidelines for cancer pain relief a 10-year prospective study. pain, 1995. 63 p. 65-76.

6. Smith HS, Deer TR, Staats PS, Singh V, Sehgal N, and Cordner H, Intrathecal drug delivery. Pain Physician, 2008. 11 (Suppl.): p. S89-S104.

7. Bentley J N, V.A., Rosenberg W S, Patil P G,, Treatment of Medically Refractory Cancer Pain with a Combination of Intrathecal Neuromodulation and Neurosurgical Ablation:Case Series and Literature Review. Pain Medicine, 2014. 15: p. 1488-1495.

8. A,etc., H.M.D.D.M.S.I., A Prospective, Randomized, Single-Blinded, Head-to-Head Long-Term Outcome Study, Comparing Intrathecal (IT) Boluses With Continuous Infusion Trialing Techniques Prior to Implantation of Drug Delivery Systems (DDS) for the Treatment of Severe Intractable Chronic Nonmalignant Pain. Neuromodulation, 2015. 18(7): p. 636-48; discussion 649. 
9. Anghelescu, D.L., Steen, B. D, et al., Prospective study of neuropathic pain after definitive surgery for extremity osteosarcoma in a pediatric population. Pediatr Blood Cancer, 2017. 64(3).

10. Piano, V., et al., Diagnosing neuropathic pain in patients with cancer: comparative analysis of recommendations in national guidelines from European countries. Pain Pract, 2013. 13(6): p. 433-9.

11. Sindhi V, M.E.M., Interventional treatments for metastatic bone cancer pain. Pain Management, 2019. 9(3): p. 307-315.

12. G Walker, A.W., C Manderson, R Weller and V Crosby, The acceptability of different routes of administration of analgesia for breakthrough pain. Palliative Medicine, 2003. 17:: p. 219-221.

13. Mercadante, S., Breakthrough pain in cancer patients: prevalence, mechanisms and treatment options. Curr Opin Anaesthesiol, 2015. 28(5): p. 559-64.

14. Gatti, A., et al., Beyond the traditional definition of breakthrough pain: an observational study. Adv Ther, 2013. 30(3): p. 298-305.

15. Brogan S E, B.M.B., and Winter N B, Patient-Controlled Intrathecal Analgesia for the Management of Breakthrough Cancer Pain: A Retrospective Review and Commentary. Pain Medicine, 2011. 12. p. $1758-1768$.

16. Brogan, S.E., N.B. Winter, and A. Okifuji, Prospective Observational Study of Patient-Controlled Intrathecal Analgesia: Impact on Cancer-Associated Symptoms, Breakthrough Pain Control, and Patient Satisfaction. Reg Anesth Pain Med, 2015. 40(4): p. 369-75.

17. Rainov N G, H.V., and Burkert W, Long-Term Intrathecal Infusion of Drug Combinations for Chronic Back and Leg Pain. Journal of Pain and Symptom Management, 2001. 22(4): p. 862-871.

18. Kim, J.H., Jung, J. Y,Cho, M. S., Continuous intrathecal morphine administration for cancer pain management using an intrathecal catheter connected to a subcutaneous injection port: a retrospective analysis of 22 terminal cancer patients in korean population. Korean J Pain, 2013. 26(1): p. 32-8.

19. Qin, W., et al., Intrathecal Morphine Infusion Therapy via a Percutaneous Port for Refractory Cancer Pain in China: An Efficacy, Safety and Cost Utilization Analysis. J Pain Res, 2020. 13: p. 231-237.

20. Ju, Y., et al., Palliative care with cervical intrathecal infusion and external pump for a late-stage cancer patient with refractory pain: A case report. Medicine (Baltimore), 2018. 97(4): p. e9714.

21. Galica, R.J., et al., Intrathecal Trialing of Continuous Infusion Combination Therapy With Hydromorphone and Bupivacaine in Failed Back Surgery Patients. Neuromodulation, 2018. 21(7): p. 648-654.

22. McRoberts W P, A.C., Intrathecal Bupivacaine Monotherapy with a Retrograde Catheter for the Management of Complex Regional Pain Syndrome of the Lower Extremity. Pain Physician, 2016. 19: p. E1087-E1092.

23. Webster L R, S.K.A., Narayana A, and Yang R, Fentanyl Buccal Tablet Compared with ImmediateRelease Oxycodone for the Management of Breakthrough Pain in Opioid-Tolerant Patients with Chronic Cancer and Noncancer Pain: A Randomized, Double-blind, Crossover Study Followed by a 12Week Open-Label Phase to Evaluate Patient Outcomes. Pain Medicine, 2013. 14: p. 1332-1345. 
24. Lohre, E.T., M. Thronaes, and P. Klepstad, Breakthrough cancer pain in 2020. Curr Opin Support Palliat Care, 2020. 14(2): p. 94-99.

25. Backryd E, L., B, Movement-evoked breakthrough cancer pain despite intrathecal analgesia: a prospective series. Acta Anaesthesiol Scand, 2011. 55(9): p. 1139-46.

26. Deer, T.R., et al., The Polyanalgesic Consensus Conference (PACC): Recommendations on Intrathecal Drug Infusion Systems Best Practices and Guidelines. Neuromodulation, 2017. 20(2): p. 96-132.

27. Bhatia, G., et al., Intrathecal Drug Delivery (ITDD) systems for cancer pain. F1000Res, 2013. 2: p. 96.

28. Shah, R., A. Baqai-Stern, and A. Gulati, Managing intrathecal drug delivery (ITDD) in cancer patients. Curr Pain Headache Rep, 2015. 19(6): p. 20.

29. De Andres, J., et al., Intrathecal Drug Delivery. Methods Mol Biol, 2020. 2059: p. 75-108.

\section{Tables}

Table1. Baseline patient characteristics

\begin{tabular}{|lll|}
\hline Age, years (mean, standard deviation) & $48 \pm 8$ & \\
\hline Male sex & $7 / 12$ & \\
\hline Type of cancer & $\begin{array}{l}\text { Osteosarcoma/ } \\
\text { fibrosarcoma }\end{array}$ & $\begin{array}{l}\text { bone metastatic } \\
\text { tumor }\end{array}$ \\
\hline Months since diagnosis (mean) & 18 (month) & \\
\hline Reason for IT therapy & poorly controlled pain & intolerance \\
\hline Pain site & Leg & \\
\hline Cather tip location & T12 & \\
\hline $\begin{array}{l}\text { Morphine nonintrathecal equivalent dose, } \\
\text { (mg/day) }\end{array}$ & $360 \pm 71 \mathrm{mg}$ & \\
\hline Patients using MEBTP opioids (mg/day) & $87 \pm 18 \mathrm{mg}$ & \\
\hline Baseline NRS pain score & $8 \pm 0.3$ & \\
\hline Mean duration of intrathecal therapy/months & $4 \pm 0.8$ & \\
\hline
\end{tabular}

IT = intrathecal; NRS = numerical rating scale

Table2. NRS pre- and post-ITT, Onset time for MEBTP 


\begin{tabular}{|llllll|}
\hline & $\begin{array}{l}\text { Pre- } \\
\text { implant } \\
\text { Mean }\end{array}$ & $\begin{array}{l}\text { Pre-implant Standard } \\
\text { deviation }\end{array}$ & $\begin{array}{l}\text { Post- } \\
\text { implant } \\
\text { Mean }\end{array}$ & $\begin{array}{l}\text { Post-implant } \\
\text { Standard } \\
\text { deviation }\end{array}$ & $\mathrm{P}$ \\
\hline SRPI & 8.75 & 1.05 & 3.75 & 0.86 & $\mathrm{P}<0.05$ \\
\hline MEPI & 8.83 & 0.93 & 4.25 & 0.96 & $\mathrm{P}<0.05$ \\
\hline $\begin{array}{l}\text { Onset time for MEBTP } \\
\text { (min) }\end{array}$ & 38.75 & 14.63 & 8 & 2.21 & $\mathrm{P}<0.05$ \\
\hline
\end{tabular}

Table3. Non intrathecal Opioid Medication Use

\begin{tabular}{|c|c|c|c|c|c|c|}
\hline & $\mathrm{N}$ & $\begin{array}{l}\text { Pre- } \\
\text { implant }\end{array}$ & $\begin{array}{l}\text { Pre- } \\
\text { implant }\end{array}$ & $\begin{array}{l}\text { Post- } \\
\text { implant }\end{array}$ & $\begin{array}{l}\text { Post- } \\
\text { implant }\end{array}$ & $\mathrm{P}$ \\
\hline & & Mean & Median & Mean & Median & \\
\hline $\begin{array}{l}\text { Morphine oral equivalent dose } \\
\text { (mg/day) }\end{array}$ & 12 & 360 & 322.5 & 48 & 40 & $P<0.05$ \\
\hline $\begin{array}{l}\text { Breakthrough morphine oral } \\
\text { equivalent dose (mg/day) }\end{array}$ & 12 & 87 & 80 & 6 & 0 & $P<0.05$ \\
\hline
\end{tabular}

Table4. Intrathecal Pump Medications

\begin{tabular}{|c|c|c|c|c|c|c|}
\hline & & \multicolumn{2}{|c|}{$\begin{array}{l}\text { baseline } \\
\text { dose }\end{array}$} & \multicolumn{2}{|c|}{ Follow up } & \\
\hline & & Mean & SE & Mean & SE & \\
\hline $\begin{array}{l}\text { Intrathecal opioid in morphine equivalent dose } \\
\text { (mg/day) }\end{array}$ & 12 & 1.85 & 0.36 & 27.87 & 4.24 & $P<0.05$ \\
\hline Intrathecal I bupivacaine (mg/day) & 12 & 0.94 & 0.17 & 14.54 & 1.55 & $P<0.05$ \\
\hline PCIA opioid in morphine equivalent dose (mg/day) & 12 & 0.65 & 0.12 & 12.73 & 2.05 & $\mathrm{P}<0.05$ \\
\hline PCIA bupivacaine dose (mg) & 12 & 0.33 & 0.06 & 6.48 & 0.60 & $\mathrm{P}<0.05$ \\
\hline Infusion speed & 12 & 0.11 & 0.01 & 0.99 & 0.05 & $\mathrm{P}<0.05$ \\
\hline Frequency of PCIA use (times/day) & 12 & 13.08 & 0.41 & 20.25 & 0.61 & $P<0.05$ \\
\hline
\end{tabular}

Table5. Opioid-related Side Effects and Technical Complications 


\begin{tabular}{|lll|}
\hline Pharmacological side effects & Pre-implant & Post-implant \\
\hline Pruritus & $1 / 12$ & $2 / 12$ \\
\hline Dizziness & $1 / 12$ & $1 / 12$ \\
\hline Nausea and vomiting & $4 / 12$ & $4 / 12$ \\
\hline Respiratory depression & $2 / 12$ & $2 / 12$ \\
\hline Constipation & $5 / 12$ & $5 / 12$ \\
\hline Urinary retention & $1 / 12$ & $3 / 12$ \\
\hline Technical complications & \\
\hline Postdural puncture headache due to cerebrospinal fluid leak & $0 / 12$ & $2 / 12$ \\
\hline
\end{tabular}

Figures

NRS Pain Scores
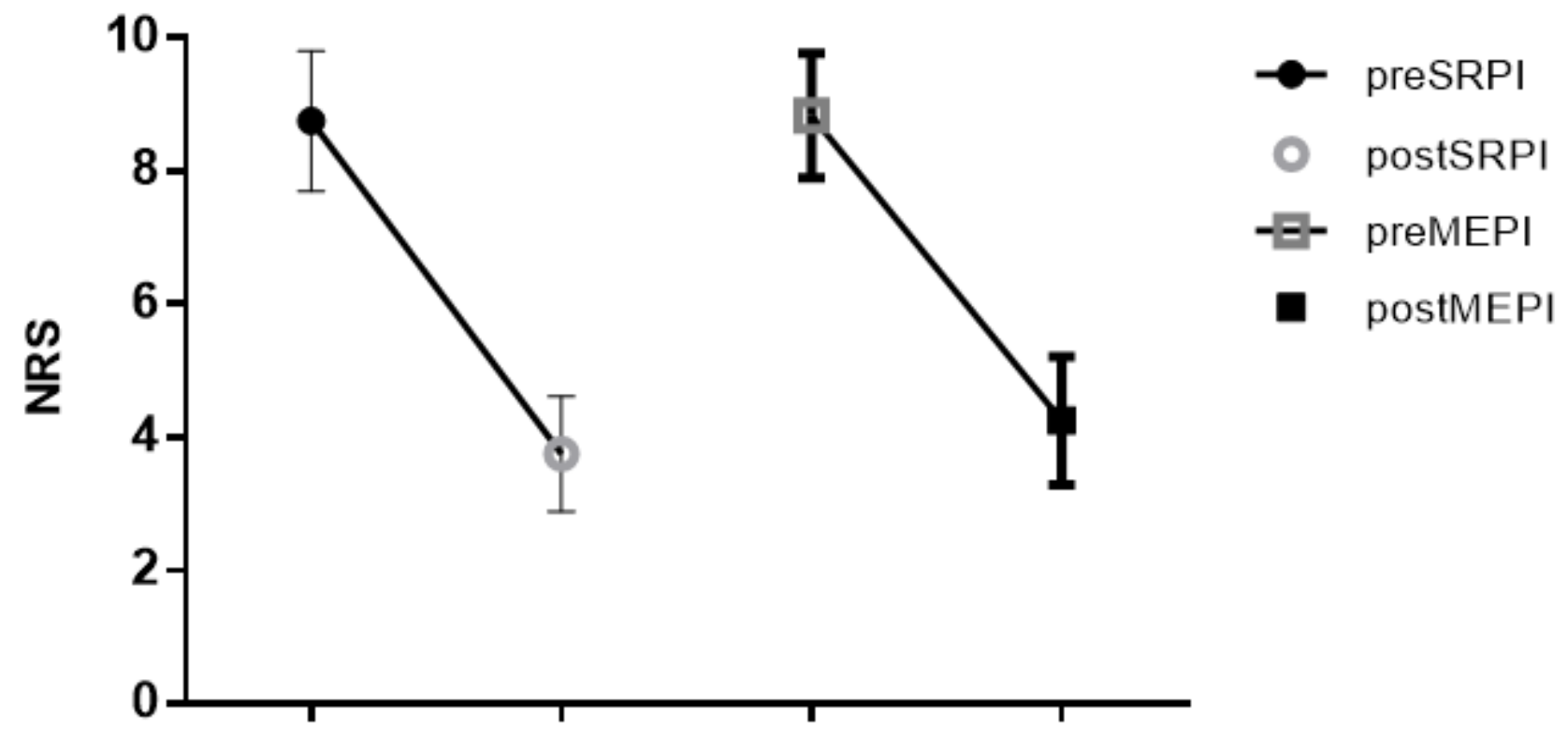

Figure 1

Legend not included with this version 


\section{Onset time for MEBTP}

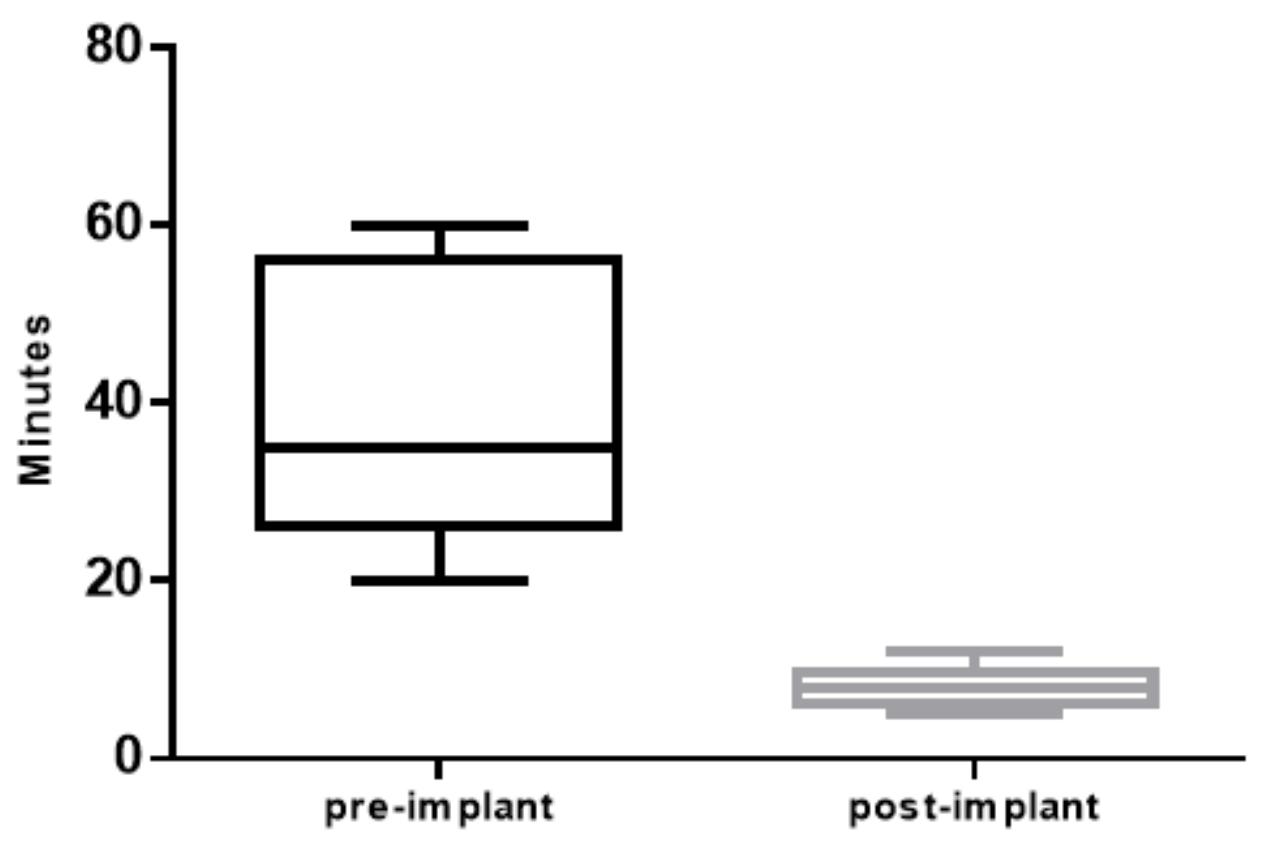

Figure 2

Legend not included with this version 